\title{
Platypnea-Orthodeoxia: Patent Foramen Ovale Unmasked by Pulmonary Emboli
}

\author{
Grainne Gallagher ${ }^{1}$, Alex Joseph², Rajkumar Rajendram ${ }^{3,4}$ \\ 1'Department of Intensive Care, Barnet General Hospital, Barnet, England, ${ }^{2}$ Department of Anaesthesiology, Changi General Hospital, Simei, Singapore, ${ }^{3}$ Department \\ of Medicine, King Abdulaziz Medical City, Ministry of National Guard Health Affairs, Riyadh, Saudi Arabia, ${ }^{4}$ Department of Anaesthesia and Intensive Care, Stoke \\ Mandeville Hospital, Aylesbury, UK
}

\section{Abstract}

This report describes an 84 year old woman who presented with breathlessness from platypnea-orthodeoxia. This was due to a distortion of a patent foramen ovale by lower thoracic vertebral fractures which allowed a right-to-left intracardiac shunt. The right-to-left shunt was, in this case, triggered by small bilateral pulmonary emboli. Platypnea-orthodeoxia is rare, complex, and underdiagnosed. The pathogenesis requires an anatomical substrate for a shunt and a functional component that triggers reversal of the flow across it. Recognition is critical and may prevent provision of sedation, invasive ventilatory support, and vasopressor; all of which actually exacerbate right-to-left extrapulmonary shunt.

Keywords: Dyspnea, hypoxia, patent foramen ovale, shunt

\section{INTRODUCTION}

Platypnea-orthodeoxia is most commonly due to reversal of flow across a patent foramen ovale (PFO). This can be diagnosed at the bedside using echocardiography with agitated saline microbubble contrast. However, the use of this bubble contrast can cause transient worsening of hypoxemia. So, while this investigation should be considered for patients with unexplained positional hypoxia, it must be avoided in patients who are critically hypoxic.

Cure requires definitive correction of the anatomical substrate (i.e., PFO). However, platypnea-orthodeoxia may improve as the functional precipitant of the right-to-left shunt resolves. Anticoagulation is also important, particularly after a venous thromboembolism as paradoxical emboli may occur.

\section{Case Report}

An 84 year old woman was referred to the hospital by her general practitioner after seeing her for the second time in 2 weeks for breathlessness. Her symptoms had worsened despite a course of antibiotics for a suspected chest infection. Before this, her exercise tolerance had been good and she had been living independently in her own home.

Her medical history included a fall 2 years before this presentation. The fall had resulted in T9-T12 vertebral crush

\begin{tabular}{|l|l|}
\hline \multicolumn{3}{|c|}{ Access this article online } \\
\hline Quick Response Code: & Website: \\
& www.ijrconline.org \\
\hline
\end{tabular}

fractures and a fractured neck of femur for which she required a dynamic hip screw.

The patient reported breathlessness and bilateral, anterior, pleuritic chest pain but denied cough and fever. She was tachypneic (22 breaths/min) and cyanosed. Only $\mathrm{SpO}_{2}$ of $85 \%$ could be achieved despite administration of $15 \mathrm{~L} / \mathrm{min}$ oxygen through a nonrebreathing mask. Her heart rate was 96 beats/min (sinus rhythm), and blood pressure (BP) was 90/40 $\mathrm{mmHg}$, but she was afebrile. Examination of her cardiovascular and respiratory systems was otherwise normal. Arterial blood gases were $\mathrm{pH} 7.42, \mathrm{PaCO}_{2} 4.0 \mathrm{kPa}, \mathrm{PaO}_{2} 7 \mathrm{kPa}$ (on $15 \mathrm{~L} / \mathrm{min} \mathrm{O}_{2}$ via a nonrebreathing facemask), bicarbonate $25 \mathrm{mmol} / \mathrm{L}$, and lactate $3.0 \mathrm{mmol} / \mathrm{L}$. Although the patient tolerated a trial of continuous positive airway pressure, the hypoxia did not improve.

An electrocardiograph was normal and a chest X-ray demonstrated the thoracic vertebral fractures, but was otherwise unremarkable. However, computed tomography pulmonary angiography (CTPA) revealed small, bilateral, subsegmental pulmonary emboli (PE); [Figure 1]. In view of albeit mild,

Address for correspondence: Dr. Rajkumar Rajendram, Department of Anaesthesia and Intensive Care, Stoke Mandeville Hospital, Aylesbury, Buckinghamshire, UK. E-mail: rajkumarrajendram@doctors.org.uk

This is an open access article distributed under the terms of the Creative Commons Attribution-NonCommercial-ShareAlike 3.0 License, which allows others to remix, tweak, and build upon the work non-commercially, as long as the author is credited and the new creations are licensed under the identical terms.

For reprints contact: reprints@medknow.com

How to cite this article: Gallagher $G$, Joseph $A$, Rajendram R. Platypnea-orthodeoxia: Patent foramen ovale unmasked by pulmonary emboli. Indian J Respir Care 2018;7:50-2. 
Gallagher, et al.: Platypnoea orthodeoxia: Unmasking of patent foramen ovale

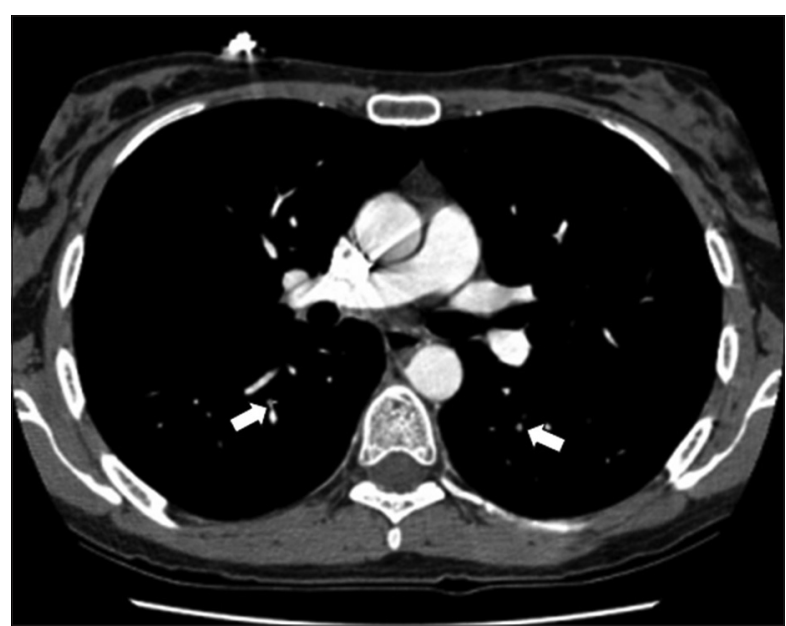

Figure 1: This slice from a computed tomography pulmonary angiogram demonstrates small, bilateral subsegmental pulmonary emboli (arrowed)

hypotension, and severe hypoxia, she was transferred to the Intensive Therapy Unit (ITU) for further observation and thrombolysed with tenecteplase. This improved her BP and $\mathrm{SpO}_{2}$ significantly.

The next morning, while asleep in the ITU, the patient's $\mathrm{SpO}_{2}$ was $98 \%$ on $2 \mathrm{~L} / \mathrm{min}$ oxygen through nasal cannula. However, on being sat out in a chair for breakfast, her $\mathrm{SpO}_{2}$ unexpectedly dropped to $80 \%$ and failed to improve with high flow oxygen. As the patient was returned to bed, in preparation for initiation of ventilatory support, her $\mathrm{SpO}_{2}$ rapidly improved to $100 \%$ as she lay flat. The patient was kept supine, and the supplemental oxygen was rapidly weaned back to $2 \mathrm{~L} / \mathrm{min}$.

A bedside transthoracic echocardiogram revealed right-to-left interatrial flow on color Doppler (Qp: Qs 0.7) which was confirmed with saline bubble contrast [Figure 2]. Cardiac catheterization demonstrated that the intracardiac pressures were normal and revealed that the PFO was too small to close.

Anticoagulation with warfarin was started and the patient was transferred out of ITU to the respiratory ward. The orthodeoxia gradually improved and serial echocardiography confirmed the reduction of the right-to-left shunt. Four weeks after presentation to hospital, the patient was discharged to a nursing home with supplemental oxygen as required for ambulation.

\section{Discussion}

Platypnea-orthodeoxia is a striking clinical syndrome, the principal symptom of which is dyspnea. It must be considered if dyspnea and hypoxemia are positional and paradoxically relieved when recumbent (platypnea) and exacerbated when upright (orthodeoxia). While this phenomenon can be caused by severe ventilation/perfusion pulmonary mismatching or pulmonary arteriovenous malformations; it is most commonly due to right-to-left shunt across an intracardiac communication. ${ }^{[1]}$

Blood usually flows from the left-to-right across a shunt, down a pressure gradient. Theoretically, reversal should

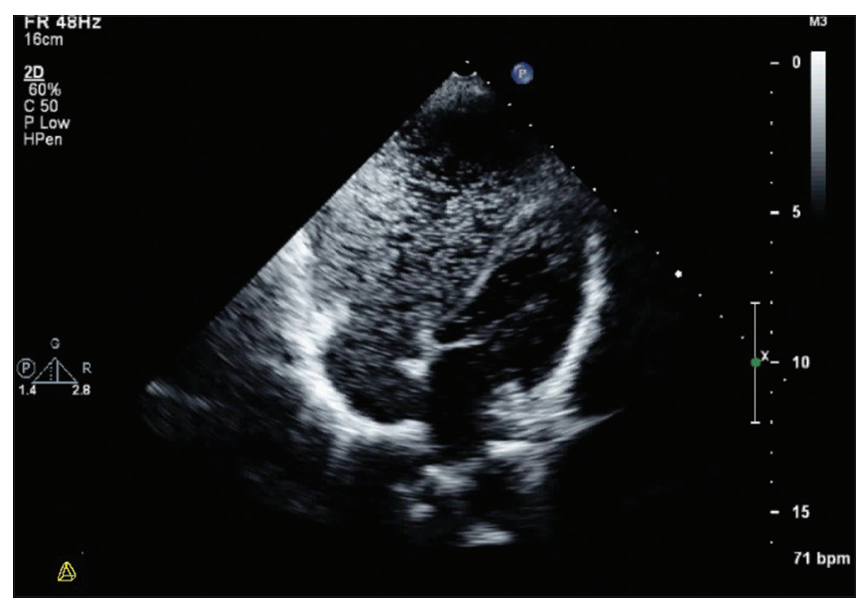

Figure 2: This microbubble contrast-enhanced two-dimensional echocardiogram shows bubbles within the left atrium and ventricle confirming the presence of an intracardiac shunt

only occur in the presence of higher right-sided pressures. Remarkably, patients with platypnea-orthodeoxia usually have normal right heart pressures. ${ }^{[2]}$ Hence, the pathogenesis of platypnea-orthodeoxia is complex and requires: ${ }^{[3]}$

1. An anatomical component (e.g. interatrial communication)

2. A functional component that

a. preferentially directs blood flow through the anatomical component

b. transiently increases right atrial pressures.

In the present case, the anatomical component was a PFO which was probably distorted by reduction in the patient's height when in the sitting position as a result of her thoracic vertebral fractures. The right-to-left shunt across the PFO which improved with anticoagulation and time is likely to have been precipitated by bilateral PE.

Although the prevalence of PFO is up to $25 \%$ within the general population, ${ }^{[4]}$ this is underdiagnosed in critically ill patients. ${ }^{[2,3,5]}$ In one series, nearly $20 \%$ of those with the acute respiratory distress syndrome (ARDS) also had moderate-to-large PFOs with shunting. ${ }^{[5]}$ This cohort respond poorly to positive end-expiratory pressure (PEEP), are ventilated longer, receive more adjuncts to improve oxygenation, and have longer admissions in ICU. ${ }^{[5,6]}$

There are no data from randomized controlled clinical trials to guide decision-making in these patients. However, if required, it is important to recognize that PEEP may exacerbate right-to-left shunt and worsen hypoxia. ${ }^{[6]}$ Hence, the best strategy is probably to target the lowest possible mean airway pressures by frequent titration of supplemental oxygen, plateau pressure and PEEP against $\mathrm{O}_{2}$ saturation, hemodynamics, and arterial blood gases. As the shunt improves, higher levels of PEEP may be tolerated but may prevent closure of the PFO.

Reducing right atrial pressure relative to left atrial pressure may also help. This may be achieved pharmacologically with inhaled nitric oxide, milrinone, sildenafil, or nitrates. Noradrenaline 
in high doses may cause pulmonary vasoconstriction and trigger shunt reversal. ${ }^{[7]}$ However, systemic vasodilation which reduces left-sided pressures should equally be avoided as it risks cardiovascular collapse in this context.

Recognition of platypnea-orthodeoxia by simply repositioning the patient recumbent may prevent the need for sedation, mechanical ventilation, and vasopressors. However, keeping the patient flat is not a viable long-term solution. While the altered physiology that triggered the right-to-left shunt must clearly be addressed; definitive treatment requires diagnosis of the anatomical substrate for platypnea-orthodeoxia.

Imaging can distinguish cardiac from pulmonary causes of shunt and define the anatomy. For example, CTPA and ventilation/perfusion scan can detect pulmonary abnormalities, and intravenous bubble contrast enhanced echocardiography can accurately demonstrate cardiac anatomy revealing the intracardiac shunt. ${ }^{[3]}$

Microbubble contrast $(10 \mathrm{ml})$ can be prepared by agitation of normal saline $(8 \mathrm{ml})$ with air $(1 \mathrm{ml})$ and a few drops of the patient's blood ( $1 \mathrm{ml}$ ) between two Luer lock syringes connected through a 3-way stopcock. When rapidly injected intravenously microbubbles within the saline should completely opacify the right heart. This appears as a "snowstorm" on two-dimensional echocardiography [Figure 2]. The bubbles are normally filtered and disperse during passage through the pulmonary circulation. Hence, any bubbles appearing in the left heart within 4 cardiac cycles confirm the presence of a right-to-left intracardiac shunt. ${ }^{[3]}$ Bubbles appearing "late" suggest that a pulmonary arteriovenous malformation is present. While the sensitivity of transesophageal echocardiography is greater than that of transthoracic echocardiography, this can be increased further with a Valsalva maneuver during administration of the microbubble contrast. Although there are rarely any complications associated with this investigation, bubble contrast may cause transient worsening of hypoxia and so should not be used in patients with critical hypoxia.

After identification of the anatomical substrate for the shunt, definitive treatment of platypnea orthodexia requires its closure. This may be achieved surgically or percutaneously. ${ }^{[3,8]}$ However, as demonstrated in this case, platypnea-orthodeoxia may improve spontaneously as the functional trigger for the right-to-left shunt resolves.

\section{Declaration of patient consent}

The authors certify that they have obtained all appropriate patient consent forms. In the form the patient(s) has/have given his/her/their consent for his/her/their images and other clinical information to be reported in the journal. The patients understand that their names and initials will not be published and due efforts will be made to conceal their identity, but anonymity cannot be guaranteed.

\section{Financial support and sponsorship}

Nil.

\section{Conflicts of interest}

There are no conflicts of interest.

\section{REFERENCES}

1. Hegland DD, Kunz GA, Harrison JK, Wang A. A hole in the argument. N Engl J Med 2005;353:2385-90.

2. Rao PS. Transcatheter management of platypnea-orthodeoxia syndrome. J Invasive Cardiol 2004;16:583-4.

3. Knapper JT, Schultz J, Das G, Sperling LS. Cardiac platypnea-orthodeoxia syndrome: An often unrecognized malady. Clin Cardiol 2014;37:645-9.

4. Hagen PT, Scholz DG, Edwards WD. Incidence and size of patent foramen ovale during the first 10 decades of life: An autopsy study of 965 normal hearts. Mayo Clin Proc 1984;59:17-20.

5. Mekontso Dessap A, Boissier F, Leon R, Carreira S, Campo FR, Lemaire F, et al. Prevalence and prognosis of shunting across patent foramen ovale during acute respiratory distress syndrome. Crit Care Med 2010;38:1786-92.

6. Védrinne JM, Duperret S, Gratadour P, Barthélémy C, Motin J. Effects of mechanical ventilation with PEEP on right to left intra-cardiac shunt caused by patent foramen ovale. Ann Fr Anesth Reanim 1995;14:387-92.

7. Hermans GM, Wilmer A, Knockaert DC, Bobbaers H. Acute intracardiac right-to-left shunt in a patient with acute respiratory distress syndrome and shock successfully treated with nitric oxide. Br J Anaesth 2006;96:268-9.

8. Blanche C, Noble S, Roffi M, Testuz A, Müller H, Meyer P, et al. Platypnea-orthodeoxia syndrome in the elderly treated by percutaneous patent foramen ovale closure: A case series and literature review. Eur J Intern Med 2013;24:813-7. 